\title{
A study of 54 cases of left displacement of the abomasum: February to July 2005
}

\author{
Sexton, M.F. ${ }^{1}$, Buckley, W. ${ }^{1}$ and Ryan, E. ${ }^{2}$
}

1 Riverview Veterinary Clinic, Bandon, Co. Cork, Ireland

2 School of Agriculture, Food Science \& Veterinary Medicine, UCD, Belfield, Dublin 4, Ireland

\begin{abstract}
Fifty-four cows with left displacement of the abomasum (LDA) submitted to the hospital facility at Riverview Veterinary Clinic from February to July 2005 were treated by right flank laparotomy and omentopexy. Five cows died (a survival rate $90.7 \%$ ) and one cow (1.8\%) was culled due to recurrence of the LDA post-operatively. Forty-one cows (76\%) returned to good production post-operatively. Thirty-nine cows (72\%) were pregnant six months after corrective surgery.
\end{abstract}

Key words: cow, abomasum, diagnosis, omentopexy, surgery, displacement

$\underline{\text { Irish Veterinary Journal }}$ Volume 60 Number 10, 605-609 2007

\section{Introduction}

Left displacement of the abomasum (LDA) mainly affects high yielding lactating dairy cows during the first month postpartum (Lotthammer, 1992), and was first described in the 1950s (Moore, 1954). Many techniques have been employed including: the left paralumbar abomasopexy or 'Utrecht' method (Baird and Harrison, 2001); the right paralumbar omentopexy or 'Hannover technique' (Dirksen, 1962); the 'toggle pin' method (Sterner-Gymer, 1982); the ventral laparoscopic abomasopexy method (Mulon, 2006); and, more recently, the two-step laparoscopic-Janowitz technique (Verhoef, 2005). LDA surgery was initially performed the authors' veterinary clinic in the late 1970s (Kelleher, pers. comm.). In this paper, the current approach to surgical correction of LDA at this clinic is described.

\section{Materials and methods}

All LDA cases were diagnosed after hearing classical resonant sounds (i.e., 'pings') on simultaneous auscultation and percussion of the left flank, especially over the last three ribs during the clinical examination.

Following diagnosis, surgery was performed within 24 hours. Surgery involved a right paralumbar laparotomy and omentopexy. The right paralumbar fossa area was surgically prepared. A $2 \%$ lidocaine solution (Norocaine; Norbrook Laboratories, Newry, Northern Ireland) was infused in an inverted 'L-shape' fashion. A $20 \mathrm{~cm}$ vertical skin incision was made at the centre of the sublumbar fossa, $10 \mathrm{~cm}$ caudal to the most posterior aspect of the last rib. The external oblique muscle was incised in a similar fashion. The internal oblique was incised bluntly along its fibres, whilst the transversalis muscle and peritoneum were incised vertically. The surgeon's hand was placed inside the abdominal cavity, lightly touching the peritoneal surface of the body wall. The abomasum was located by moving the hand down the right abdominal wall to the floor and up the other side, under the rumen. Previously, the trapped gas would have been released using a needle and rubber tubing reaching to the exterior; however, in the last few years the gas has been released by pushing the abomasum down to the midline and replacing it into its correct position on the right hand side of the abdomen. The pyloric sphincter region and proximal duodenum were exteriorised so that the omentum adjacent to the sphincter region ('Sow's ear') could be visualised. An area of omentum, $2 \mathrm{~cm} \times 2 \mathrm{~cm}$ within $5 \mathrm{~cm}$ of the pyloric sphincter, was stitched in a continuous 'through and through' pattern, using a polyamide suture (USP $3 \& 4 / \mathrm{EP} 6$ ) and a round-bodied needle. The two ends of the polyamide were sutured through the peritoneum and transversalis muscle and tied with a simple suture midway between the abdominal incision and the final rib. The peritoneum/transversalis layer and both abdominal muscles were sutured separately using chromic catgut (USP 3/EP 7 ) in a simple continuous fashion. The skin was closed using the aforementioned polyamide in a continuous Ford interlocking pattern.

Four cows in a shocked state were given hypertonic saline $(5 \mathrm{ml} / \mathrm{kg}$ of $7.2 \% \mathrm{NaCL}, 31$ infusion for a $600 \mathrm{~kg}$ cow over five to six minutes) post-operatively. All cows were treated with penicillin and streptomycin (Pen-Strep; Norbrook Laboratories, Newry, Northern Ireland), propylene glycol $(200 \mathrm{ml}$ BID for the first day and $100 \mathrm{ml}$ BID for three further days) and ruminal stimulants, $1 \times 100 \mathrm{~g}$ BID (Stimulex; Biofac A/S, Denmark) for four days postoperatively. Any concurrent diseases were also treated. Metritis cases were treated with ceftiofur hydrochloride (Excenel RTU; Pfizer Animal Health, Ringaskiddy, Co. Cork) parenterally and intrauterine cephapirin (Metricure; Intervet, Boxmeer, the Netherlands). Mastitis cases were treated with trimethoprim sulphadiazine (Norodine 24\%; Norbrook Laboratories, Newry, Northern Ireland). 


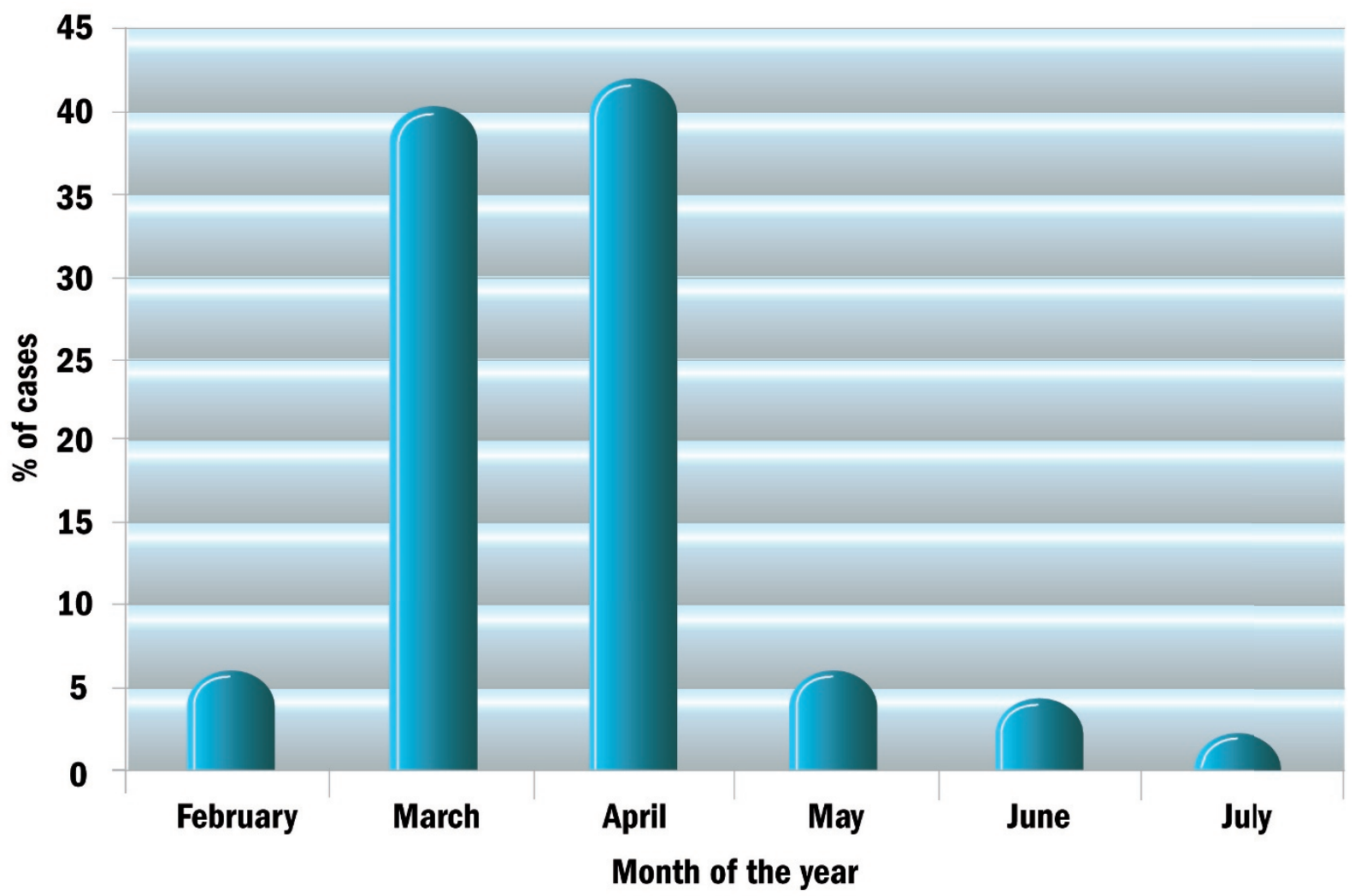

Figure 1: LDA cases (\%) by month of the year.

Cows were discharged either on the day of surgery or on the following day, with a recommendation of once-daily milking and hay feeding for three to four days, with a gradual reintroduction to concentrate ration and to the rest of the herd.

On the day of diagnosis of LDA, details of each case were taken, including: length of time calved; lactation number; average annual yield of cow and herd; and, any concurrent diseases at or since calving. Several months later, clients were telephoned to determine whether cows survived postsurgery, how they had milked and whether they were going to continue in the herd.

\section{Results}

\section{Seasonality}

The majority of cases in this study occurred in March and April (Figure 1).

\section{Post-partum interval to disease}

Ten cases $(25 \%)$ of LDA occurred in each of the first three weeks postpartum (Table 1).

Table 1: Time interval from parturition to LDA surgery in 40 cows

\begin{tabular}{|c|c|l|}
\hline Time interval (days) & No. of cases & $\begin{array}{l}\text { Percentage of cases } \\
(\%)\end{array}$ \\
\hline$\leq 3$ & 2 & 5.0 \\
\hline $4-7$ & 8 & 20.0 \\
\hline $8-14$ & 10 & 25.0 \\
\hline $15-21$ & 10 & 25.0 \\
\hline $22-28$ & 5 & 12.5 \\
\hline$\geq 29$ & 5 & 12.5 \\
\hline
\end{tabular}

\section{Lactation number}

The distribution of surgical cases by lactation number is shown in Table 2.

Table 2: Distribution of 39 cows with LDA as defined by lactation number

\begin{tabular}{|c|c|l|}
\hline Lactation number & No. of cases & Percentage of cases (\%) \\
\hline 1 & 13 & 33.3 \\
\hline 2 & 8 & 20.5 \\
\hline 3 & 7 & 17.9 \\
\hline 4 & 4 & 10.0 \\
\hline 5 & 2 & 5.0 \\
\hline 6 & 0 & 0 \\
\hline 7 & 3 & 7.7 \\
\hline 8 & 2 & 5.1 \\
\hline
\end{tabular}

\section{Milk yield}

The predicted 305-day milk yield for the surgery cases is shown in Table 3.

\section{Concurrent disease}

On clinical examination, concurrent disease was found in 33 of 54 cases (61.1\%) of LDA (Figure 2). Three-quarters $(76 \%)$ of all cases of concurrent disease were related to the reproductive tract, including retained foetal membranes $(15 \%)$, metritis $(37 \%)$ and vaginitis secondary to trauma following dystocia (24\%).

\section{Analysis of surgical intervention}

Two cows were inoperable and were euthanased because extensive adhesions throughout the abdominal cavity were found during surgery. Three cows died following surgical 
Figure 2: Concurrent disease in 33 cows with LDA.

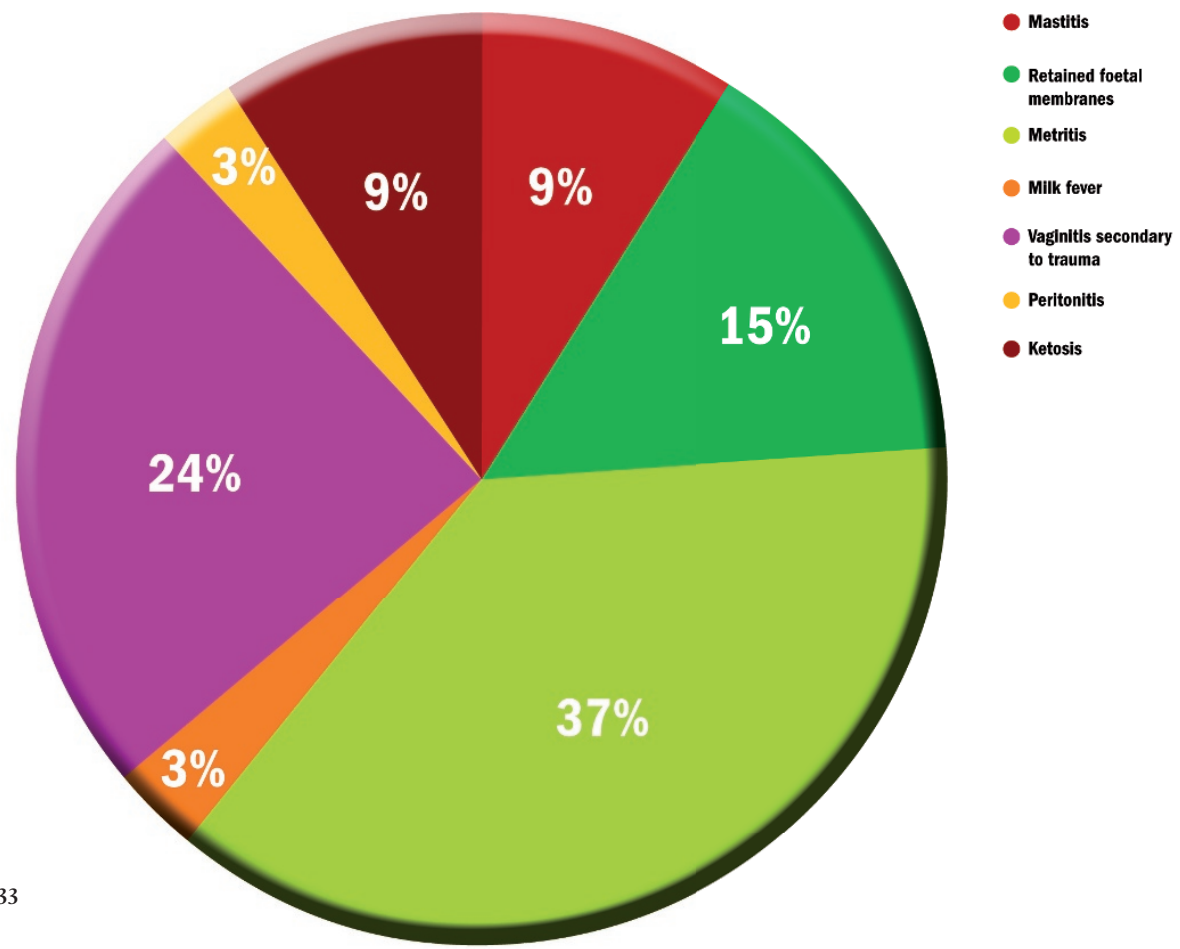

Table 3: Distribution of predicted 305-day milk yield for 40 cows treated surgically for LDA

\begin{tabular}{|l|c|c|}
\hline Milk yield (litres) & No. of cases & Percentage of cases (\%) \\
\hline$<4,500$ & 1 & 2.5 \\
\hline 5,000 & 1 & 2.5 \\
\hline 5,400 & 3 & 7.5 \\
\hline 5,900 & 10 & 25.0 \\
\hline 6,300 & 2 & 5.0 \\
\hline 6,800 & 6 & 15.0 \\
\hline 7,200 & 3 & 7.5 \\
\hline 7,700 & 2 & 5.0 \\
\hline 8,100 & 2 & 5.0 \\
\hline 8,600 & 1 & 2.5 \\
\hline 9,000 & 2 & 5.0 \\
\hline $9,001-9,899$ & 4 & 10.0 \\
\hline 9,900 & 3 & 7.5 \\
\hline
\end{tabular}

intervention (Table 4). One cow died as a consequence of fibrinous peritonitis diagnosed at surgery. However, two cows died unexpectedly after routine surgery; one cow had early fibrinous peritonitis at necropsy. The survival rate was $100 \%$ from one week post-operatively. Forty-one of the 49 cows $(83.7 \%)$ were still milking four to five months later and $39(79.6 \%)$ were pregnant.

\section{Discussion}

The prevalence of LDA on high-producing dairy farms varies from 0-7\% per annum (Cameron et al., 1998) with an increasing incidence due to rising average milk yields (Dawson et al., 1992), higher genetic merit cows, inadequate nutritional management of high yielding cows and increasing awareness amongst farmers and veterinary surgeons. The temporal occurrence of LDA, with a peak in the months of March and April in our study, coincides with the early postpartum period and peak springtime calving. An important finding of this study was that $75 \%$ of LDA cases occurred within the first three weeks postpartum. This occurrence is higher than some American studies which show only a $65 \%$ occurrence by 50 days postpartum (Petty, 1981). However, in other studies, $80 \%$ of cases occurred within 30 days of calving (Robertson, 1968; Martin, 1972 ) and $57 \%$ in the first two weeks, $80 \%$ in the first month and $91 \%$ by six weeks (Fubini and Ducharme, 2004).

It is possible that many of the cases of LDA in our study that were diagnosed during the third week postpartum could have been present earlier because the case history obtained from the client reported that the cow "had not been right" since parturition.

In addition the peak in LDA occurrence associated with high milk yielding cows ( $\geq 9,000$ litres) may be explained by the increased metabolic stress on these individuals. The peak at the 5,900 litre average milk yield may be explained by the fact that the majority of animals included in this study were young cows in their first and second lactations. These young cows naturally milk less than older cows and thus their expected average milk yield would be lower.

Our finding of $32.5 \%$ of LDA cases in primiparous animals contrasts with American research (Robertson, 1968; Martin, 1972) that reported that first-calvers had an incidence of only $18.9 \%$, second lactation an incidence of $21.7 \%$ and third lactation an incidence of $59.4 \%$. Fubini and Ducharme (2004) reported that LDA was most common in cows between four and seven years of age.

The present study finding that $61.1 \%$ of LDA cases had concurrent illness is supported by other studies whereby cows with LDA were twice as likely to have another ailment as those that did not (Detilleux et al., 1997). 
Table 4: Outcome following LDA surgery in 54 cows

\begin{tabular}{|l|c|c|}
\hline Surgical outcome & $\begin{array}{l}\text { No. of } \\
\text { cases }\end{array}$ & $\begin{array}{l}\text { Percentage of } \\
\text { cases }\end{array}$ \\
\hline $\begin{array}{l}\text { Insurmountable complications } \\
\text { discovered during surgery (e.g., } \\
\text { adhesions) }\end{array}$ & 2 & $3.7 \%$ \\
\hline $\begin{array}{l}\text { Died expectedly post-op } \\
\text { Died unexpectedly due to acute } \\
\text { peritonitis post-op }\end{array}$ & 2 & $1.9 \%$ \\
\hline $\begin{array}{l}\text { Overall survival rate } \\
\text { Recurrence rate of LDA post-op }\end{array}$ & 1 & $3.8 \%$ \\
\hline Cows milking 4-5 months post-op & 41 & $90.7 \%$ \\
\hline Cows in-calf post-op & 39 & $83.7 \%$ \\
\hline
\end{tabular}

The pathogenesis of LDA involves three factors: rumen fill; post-partum abdominal void; and, abomasal atony (Constable et al., 1992). For left abomasal displacement, space in the abdominal cavity must be created. This naturally occurs postpartum with the delivery of the calf, expulsion of the placenta and subsequent involution of the uterus. Holstein cows may be particularly predisposed to LDA due to the larger abdominal cavity (Dawson et al., 1992). This increase in abdominal space is exacerbated when the rumen is small, thus leaving space for the abomasum to displace to the left side (Dirksen, 1962). Poor rumen fill in its own right is also a major contributory factor (Constable et al., 1992). Reduced appetite after calving directly leads to reduced rumen fill and size. Also, these animals may not have access to adequate quantities of long fibre, resulting in reduced rumen function and appetite suppression. Cows that are fed finely ground rations (Dawson et al., 1992) or an excess of short fibre forages such as maize (van Winden and Kuiper, 2003) are more likely to develop an LDA due to reduced rumen fill and increased fermentation.

The final contributory influence is abomasal atony (Constable et al., 1992). Endotoxins and mediators of inflammation (e.g., histamine) released after metritis, mastitis and laminitis can lead to a reduction in abomasal motility (Correa et al., 1993). Such a hypomotile abomasum filled with gas due to excess volatile fatty acid (VFA) production displaces from its normal position to the dorsocranial aspect of the left abdominal cavity.

In this study, two cases were inoperable as there were extensive adhesions throughout the abdominal cavity making reduction and relocation of the abomasum impossible. On consultation with the owner, both cows were euthanased.

One cow died post-operatively due to the presence of a fibrinous peritonitis that appeared to be well advanced. Although the position of the abomasum was corrected and the cow was treated accordingly, the prognosis remained extremely guarded. No abomasal ulcer was detected and no other obvious aetiology was observed. This represented a rate of $1.9 \%$, compared with a rate of $1.5 \%$ achieved in a 400-case study by Verhoef (2005).

In the present study, two of 54 cows (3.8\%) died unexpectedly. Postmortem examination of one of the cows, two days post-surgery, displayed changes in peritoneal fluid and a presumptive diagnosis of peritonitis was made; no abomasal ulcer was present. This mortality rate compares with a rate of $7 \%$ in the study by Kelton et al. (1988) which compared the paramedian approach with the toggle pin technique. Single deaths were recorded from mesenteric volvulus, salmonellosis, metabolic disease and suspected pyloric stenosis (Kelton et al., 1988).

One case of LDA treated in the current study recurred (1.8\%). This may have been associated with the tearing of the polyamide suture through the fat in the omentum. This recurrence compares to $0.25 \%$ in Verhoef's two-step laparoscopic-Janowitz technique (2005). An earlier study into the rolling method found re-occurrence rates of up to $50-70 \%$ (Vlaminck et al., 1984). A recurrence rate of $1.4 \%$ was reported for both the paramedian and toggle-pin techniques (Kelton et al., 1988). A 3.3\% recurrence rate was reported for laparoscopic-guided abomasopexy (Seeger $e t$ al., 2006).

Seventy-six percent of cows were milking satisfactorily six months later, while $79 \%$ of cows that were bred were back in calf. This compares favourably with the left paralumbar omentopexy study (Vlaminck et al., 1998) but less so with the smaller study for a ventral laparoscopic abomasopexy method in a group of 17 cows (Mulon et al., 2006), with rates of $100 \%$ and $88 \%$, respectively.

A decision-tree analysis study of treatment alternatives for LDA carried out in the USA (Ruegg and Carpenter 1989), suggests that surgical treatment had the highest expected monetary value (EMV) of $\$ 1,661$. Closed surgical techniques, e.g., 'roll and tack', had an EMV of $\$ 1,636$, whilst rolling had the lowest EMV at $\$ 764$. This, however, was greater than the EMV of $\$ 480$ obtained by selling the animal.

This present study highlights the potential benefits of surgical correction of LDA in a practice setting.

\section{Acknowledgements}

The authors would like to thank: colleagues and staff at Riverview Veterinary Clinic for all their help and assistance; students Elena Nani, Torino, Lisa Ebner, Ingolstadt and Christiane Freytag, Leipzig; and the kind staff at the veterinary library, UCD.

\section{References}

Baird, A.N. and Harrison, S. (2001). Surgical treatment of left displaced abomasums. Compend Contin Educ Pract Vet 23: S102-S108.

Cameron, R. E. B., Dijk, P.B., Herdt, T.H., Kaneene, J.B., Miller, R., Bucholtz, F., Liesman, J.S., Vandehaar, M.J. and Emery, R.S. (1998). Dry cow diet, management, and energy balance as risk factors for displaced abomasum in high producing dairy herds. Journal of Dairy Science 81(1): 132-139.

Constable, P. D., Miller, G. Y., Hoffsis, G.F., Hull, B.F. and Rings, D.F. (1992). Risk factors for abomasal volvulus and left abomasal displacement in cattle. American Journal of Veterinary Research 53: 1184-1192.

Correa, M. T., Erb, H. and Scarlett, J.M. (1993). Path analysis for seven postpartum disorders of Holstein cows. Journal of Dairy Science 76: $1305-$ 1312.

Cottrell, D. F. (1994). Vagal reflex inhibition of motility in the abomasal body of sheep by antral and duodenal tension receptors. Veterinary Research 
Communications 18: 319-330.

Dawson, L. J., Aalseth, E. P., Rice L.E. and Adams, G.D. (1992). Influence of fiber form in a complete mixed ration on incidence of left displaced abomasum in postpartum dairy cows. Journal of American Medical Association 200: 1989-1992.

Detilleux, J. C., Gröhn, Y. T., Eicker, S.W. and Quaas, R.L. (1997). Effects of left displaced abomasum on test day milk yields of Holstein cows. Journal of Dairy Science 80(1): 121-126.

Dirksen, G. (1962). Dilation, displacement and torsion of the abomasum in cattle. Deutsche Tierarztl Wochenschr 68: 8-12.

Fubini, S. L. and Ducharme, N. G. (2004). Farm animal surgery. Philadelphia: Saunders.

Fubini, S.L., Ducharme, N.G., Erb, H.N., Shiels, R.L. and Hollis, N.E. (1992). A comparison in 101 dairy cows of right paralumbar fossa omentopexy and right paramedian abomasopexy for treatment of left displacement of the abomasum. Canadian Veterinary Journal 33: 318-324. Kelton, D. F., García, J., Guard C.L., Dinsmore, R.P., Powers, P.M., Smith, M.C., Stelman, S., Ralston, N. and White, M.E. (1988). Bar suture (toggle pin) vs open surgical abomasopexy for treatment of left displaced abomasum in dairy cattle. Journal of the American Veterinary Medical Association 193(5): 557-559.

Lotthammer, K. H. (1992). Epidemiological studies of the occurrence of abomasal displacement in dairy cows. Tierarztliche Umschau 47: 320-328. Martin, W. (1972). Left abomasal displacement: an epidemiological study. Canadian Veterinary Journal 13: 61-68.

Massey, C. D., Wang, C., Donovan, A. and Beeda, D.K. (1993).

Hypocalcaemia at parturition as a risk factor for left displacement of the abomasum in dairy cows. Journal of the American Veterinary Medical Association 203: 852-853.

Moore, G. R., Riley, W. F. and Westcott, R.W. (1954). Displacement of the bovine abomasum. Veterinary Medicine 49: 49-51.

Mulon, Y.P., Babkine, M. and Desrochers, A. (2006).Ventral laparascopic abomasopexy in 18 cattle with displaced abomasum. Veterinary Surgery 35: 347-355.

Petty, R. D. (1981). Surgical correction of left displaced abomasum in cattle: a retrospective study of 143 cases. Journal of the American Veterinary Medical Association 178: 1274-1276.

Robertson, J. M. (1968). Left displacement of the bovine abomasum: epizootiologic factors. American Journal of Veterinary Research 29: 421-434. Ruegg, P. L. and Carpenter, T. E. (1989). Decision-tree analysis of treatment alternatives for left displaced abomasum. Journal of the American Veterinary Medical Association 195(4): 464-467.

Seeger, T., Kumper, H., Failing, K. and Doll, K. (2006). Comparison of laparascopic-guided abomasopexy versus omentopexy via right flank laparotomy for the treatment of left abomasal displacement in dairy cows. American Journal of Veterinary Research 67(3): 472-478.

van Winden, C.L. and Kuiper, R. (2003). Left displacement of the abomasum in dairy cattle: recent developments in epidemiological and etiological aspects. Veterinary Research 34: 47-56.

Verhoef, M. (2005). Techniques for treating the left displaced abomasums (LDA), with emphasis on laparascopic repositioning and fixation in the standing cow. Proceedings of the first joint AVSPNI and CAVI conference p90-92.

Vlaminck, L., Martens, A., Steenhaut, F., Gasthuys, F., Desmet, P. and De Moor, A. (1984). Surgical correction of abomasal displacement in cows: a review of 163 cases. Vlaams Dier Tijd 201-206.

Vlaminck, L., Steenhaut, M., Gasthuys, F., Martens, A., Desmets, P., Vanden Abeele, K. and De Moor A. (1998). Omentopexy for correction of left displaced abomasum: outcome results in 53 cattle. Vlaams Dier Tijd 67: 118-122.

Whitlock, R.H. (1976). Pathophysiology of lower gastrointestinal tract problems in the bovine. Proceedings of the Ninth Annual Convention of the American Association of Bovine Practitioners p43-48. 